\title{
Value of Functional MRI in Evaluation of Ovarian Lesions
}

\author{
FATMA A. ELSHARAWY, M.D.* and NAGLAA A. HUSSEIN, M.D.** \\ The Departments of Radio-Diagnosis \& Medical Imaging* and Gynecological**, Faculty of Medicine, Tanta University, Egypt
}

\begin{abstract}
Background: Ovarian masses present a special diagnostic challenge when imaging findings cannot be categorized into benign or malignant pathology. Magnetic Resonance Imaging (MRI) is currently used to evaluate ovarian tumors. Functional MRI techniques such as Diffusion Weighted MRI (DW-MRI), Dynamic Contrast-Enhanced MRI (DCE-MRI) are currently being evaluated as possible predictive and prognostic biomarkers in the context of ovarian malignancy.

Aim of Study: Differentiation between benign and malignant ovarian lesions by conventional MRI and assessing the role of functional MRI (f-MRI) as an advanced MRI technique for better differentiation.

Patients and Methods: 30 patients with ovarian masses were included. Evaluation of functional Magnetic Resonance Imaging (f-MRI) in diagnosis of ovarian masses and differentiating the benign from malignant lesions in addition to conventional MRI sequences.

Results: Our study included 30 patients with different ovarian lesions, 22 benign cases and 8 malignant cases proved by histopathology and laparoscopy, and the mean age was 40.37 years. Imaging all have increased the sensitivity, specificity, positive and negative predictive values and accuracy from $72.7 \%, 66.7,57.14 \%, 80 \%, 61.5 \%$ respectively for conventional MRI to $90.9 \%, 100 \%, 90.9 \%, 94.7 \%, 95 \%$ respectively for f-MRI.
\end{abstract}

Conclusion: Combination of conventional MRI \& f-MRI findings are problem-solving tool for confusing ovarian lesions, characterizing benign and malignant ovarian tumors.

Key Words: f-MRI: Functional Magnetic Resonance Imaging - DCEMRI: Dynamic Contrast Enhanced Magnetic Resonance Imaging - DWMRI: Diffusion Weighted Magnetic Resonance Imaging.

\section{Introduction}

OVARIAN masses present a special diagnostic challenge when imaging findings cannot be categorized into benign or malignant pathology. Ultrasonography (US), Computed Tomography (CT), and Magnetic Resonance Imaging (MRI) are cur-

Correspondence to: Dr. Fatma A. El-Sharawy, E-Mail: elsharawyf@hotmail.com. rently used to evaluate ovarian tumors. US is the first-line imaging investigation for suspected adnexial masses helping in detection and characterization of ovarian tumors [1].

Benign ovarian diseases can simulate malignancies. The knowledge of clinical syndromes and MRI features of these conditions is crucial in establishing an accurate diagnosis and determining appropriate treatment [2].

Functional MRI techniques such as Diffusion Weighted MRI (DW-MRI), Dynamic ContrastEnhanced MRI (DCE-MRI) are currently being evaluated as possible predictive and prognostic biomarkers in the context of ovarian malignancy [3].

\section{Patients and Methods}

This prospective study included (30) female patients with different ovarian lesions conducted in the period from February 2019 to January 2020 at Tanta Unversity Hospital. Most of patients presented with vaginal bleeding and/or vague pelviabdominal pain. Patients with positive MRI findings were selected in the study, their ages ranged from 20 to 73 years, and the mean age was 40.37 years. Our institutional review board approved the study and waived the requirement to obtain written informed consent for the procedure \& the study.

\section{Our inclusion criteria were:}

- Any patient suspected to have a gynecological pelvic mass on clinical examination.

- Any patient known to have any gynecological troubles.

- Any patient known to have previous ovarian tumor.

MRI was performed using a $1.5 \mathrm{~T}$ magnet. 
Our exclusion criteria were:

- Patients with past history of cardiac pace maker or artificial valve as it is contraindicated with MRI.

- Patients having history of claustrophobia.

- Patients having renal failure were excluded from contrast administration.

All cases had been subjected to the following:

1- Full history taking with a special emphasis on:

- Age.

- Time of menarche and menopause.

- Past history of gynecological troubles or operations.

- Positive family history of gynecological malignancy

2- Routine laboratory investigation for all patients including: $\mathrm{CBC}$, random blood sugar, liver functions and kidney functions.

3- Ultrasound examination: All patients had undergone preliminary pelvic ultrasound to exclude benign functional pure cystic lesions, transabdominal and trans-vaginal ultrasound approaches using $3-4 \mathrm{MHz}$ and $7-8 \mathrm{MHz}$ probes respectively. Color Doppler was superimposed on masses to detect vascularity in some cases.

4- MR and f-MR imaging MR imaging was performed on a 1.5-T MR imaging machine [General Electric (GE) medical system].

Patient preparation:No special patient's preparation is necessary for pelvic MRI. When making an appointment for a pelvic MRI, the patient was asked about claustrophobia and any contraindications of MRI as cardiac pace maker, artificial valves and prior to the exam they were instructed to remove any metallic object. Procedure was explained for reassurance and also they were informed about the length of the examination and the value of remaining motionless. They were asked to avoid coughing or swallowing during the acquisition time.

\section{MR imaging protocol:}

Patient is positioned supine and feet first on the scan table, and she must be well centralized to ensure that both sides are in the same horizontal plane for proper coronal imaging. Patients were imaged with the pelvic phased-array coil. FOV ranges from 30 to $45 \mathrm{~cm}$ in diameter depending on the width of the entire pelvis.

Evaluation of the pelvis was done using axial, coronal and sagittal non contrast T1 and T2 weight- ed images. Post contrast fat suppressed T1 weighted image was performed for some cases for the recognition of enhancement of the solid component, the tumor wall, septations and vegetations. Fat saturation was done for all cases as a routine. The sequences used in the study are:

1- $\mathrm{T} 1$ weighted ( $\mathrm{T} 1 \mathrm{~W}$ ) image in axial plane: $\mathrm{TR}=459.95 \mathrm{msec}, \mathrm{TE}=8 \mathrm{msec}$, SLICE thickness 4 , slice gap $1.5 \mathrm{~mm}$, scan duration $1.18 \mathrm{~min}$, FOV $45 \mathrm{~cm}$, matrix $256 \times 256$.

2- T2 weighted (T2W-TSE) images (Turbo spin echo): (In axial, sagittal, and coronal plans): TR $=3500 \mathrm{msec}, \mathrm{TE}=90 \mathrm{msec}$, slice thickness 4 , slice gap $1.5 \mathrm{~mm}$, scan duration $1.17 \mathrm{~min}$, FOV $45 \mathrm{~cm}$, matrix $256 \times 256$.

3- Diffusion MRI: It was acquired in the axial plane prior to administration of contrast medium using a single-shot echo-planar imaging sequence (TR/TE effective range $=9,000-18,000 / 30-60$; slice thickness $3-5 \mathrm{~mm}$; slice gap $1.5 \mathrm{~mm}$; FOV $45 \mathrm{~cm}$; matrix $128 \times 128$; at b-value of $800 \mathrm{~s} / \mathrm{mm}^{2}$ ).

4- T1 fat suppression (STIR): (In axial, sagittal, and coronal plans): Performed after bolus injection of $0.1 \mathrm{mmol} / \mathrm{kg}$ body weight of (Gd-DTPA ScheringGermany) at a rate of $2 \mathrm{ml} / \mathrm{s}$, flushed with $20 \mathrm{ml}$ of sterile $0.9 \%$ saline solution from the antecubital vein. The injection of contrast media and saline solution was performed manually. The patient was asked to hold breath at end expiration (for post contrast cases). The parameters were as follows: $\mathrm{TR}=2726 \mathrm{msec}, \mathrm{TE}=60 \mathrm{msec}$, matrix $256 \times 256$ with a field of view $45 \mathrm{~cm}$, slice thickness $5.5 \mathrm{~mm}$, slice gap 0mm. MR images were analyzed for the following: MR appearance of the tumor; whether cystic, solid or mixed. Signal intensity of the tumor either high, low or mixed. The signal intensity of the mass on DWI on high b-values ( $>1000$ $\mathrm{sec} / \mathrm{mm}^{2}$ ) either facilitated or restricted. Signal intensity of the mass in the corresponding ADC maps. SI of any suspicious lymph nodes and/or peritoneal deposition. Pattern of enhancement either homogenous or heterogeneous or septal. Wall thickness of the tumor and its enhancement either thin or thick. Presence of vegetations, their enhancement pattern and their size. Presence of ascites.

Presence of infiltrated pelvic or para aortic lymph nodes and its size if present. Involvement of other pelvic organs. Presence of peritoneal and omental deposit. Presence of parametrial invasion.

The statistical analysis: Data were fed to the computer and analyzed using IBM SPSS software package version 20.0. Qualitative data were de- 
scribed using number and percent. Quantitative data were described using range (minimum and maximum), mean, standard deviation and median. Significance of the obtained results was judged at the $5 \%$ level.

\section{The used tests were:}

1- Chi-square test: For categorical variables, to compare between different groups.

2- Fisher's Exact: Correction for chi-square when more than $20 \%$ of the cells have expected count less than 5 .

3- Student t-test: For normally quantitative variables, to compare between two groups.

4- ROC curve: For detection of validity and cut off point in comparison to sure diagnostic test.

\section{Results}

Our study included 30 patients with different ovarian lesions, 22 benign cases and 8 malignant cases proved by histopathology and laparoscopy (Table 1).

Pelvi-abdominal pain was the most common complaint among patients under study. All of patients subjected to MRI pelvic assessment performed on 1.5T MR imaging machine with pelvic phased-array coil. The MRI protocol was T1 in axial plane, T2 in axial, coronal and sagittal, T1 (dynamic post contrast) fat saturation in axial, coronal and sagittal and diffusion weighted images. All cases MRI results were compared with pathological or laparoscopic results.

For differentiation between benign and malignant ovarian lesions most of benign ovarian lesions show type I curve (14 benign cases in our study), except some benign lesions (for example in our study: One hemorrhagic cyst case, one chocolate cyst case, one proteinaceous cyst case and three tubo-ovarian abscess cases). While most of malignant ovarian lesions show type III curve (six malignant cases in our study) with ADC value $\geq$ [OR $\leq] 1.16 \times 10^{-3} \mathrm{~mm}^{2} / \mathrm{s}$ as a cutoff point differentiating between benign and malignant ovarian lesions. Five cases which were complex cystic and solid, two cases associated with ascites and one case with papillary projections, seven cases of mixed contents and six cases which had heterogeneous pattern of enhancement proved to be malignant pathologically. Imaging all have increased from $72.7 \%, 66.7,57.2 \%, 80 \%, 61.7 \%$ respectively for conventional MRI to $90.9 \%, 100 \%, 90.9 \%$, $94.7 \%, 95 \%$ respectively for functional MRI with post-processing.
Table (1): Distribution of the studied cases according to demographic data $(n=30)$.

\begin{tabular}{ccc}
\hline & No. & $\%$ \\
\hline Age (years): & & \\
$\leq 30$ & 8 & 26.7 \\
$>30$ & 22 & 73.3 \\
Min.-max. & $18.0-45.0$ \\
Mean \pm SD. & $33.47 \pm 8.05$ \\
Median & 34.0 \\
BI $\left(\mathrm{kg}^{2} \mathrm{~m}^{2}\right):$ & \\
Min.-max. & \\
Mean \pm SD. & $26.0-28.0$ \\
Median & $27.03 \pm 0.76$ \\
\end{tabular}

Table (2): Distribution of the studied cases according to different parameters $(n=30)$.

\begin{tabular}{lll}
\hline & No. & $\%$ \\
\hline Side of mass: & 17 & 56.7 \\
$\quad$ Right & 13 & 43.3 \\
$\quad$ Left & & \\
Size: & 10 & 33.3 \\
$\quad$ Less than $6 \mathrm{~cm}$ & 20 & 66.7 \\
$\quad$ More than 6cm & & \\
Thickness of wall: & 11 & 36.6 \\
$\quad$ Less than 3cm & 19 & 63.3 \\
$\quad$ More than 3cm & 19 \\
\hline
\end{tabular}

Table (3): Distribution of the studied cases according to septations $(n=30)$.

\begin{tabular}{llc}
\hline Septated & No. & $\%$ \\
\hline No & 7 & 23.3 \\
Yes & 23 & 76.6 \\
\hline
\end{tabular}

Table (4): Distribution of the studied cases according to solid vegetation $(n=30)$.

\begin{tabular}{lcc} 
Solid vegetation & No. & $\%$ \\
\hline No & 9 & 30 \\
More than $1 \mathrm{~cm}$ & 21 & 70 \\
\hline
\end{tabular}

Table (5): Distribution of the studied cases according to conventional MRI positive characer of malignancy $(n=30)$.

\begin{tabular}{lcl}
\hline MRI positive characer of malignancy & No. & $\%$ \\
\hline Malignant & 12 & 40.0 \\
Benign & 16 & 53.3 \\
Borderline & 2 & 6.7 \\
\hline
\end{tabular}

Table (6): Distribution of the studied cases according to type of curves $(n=30)$.

\begin{tabular}{lcc}
\hline Type of curves & No. & $\%$ \\
\hline I & 18 & 60 \\
II & 4 & 13.3 \\
III & 8 & 26.6 \\
\hline
\end{tabular}




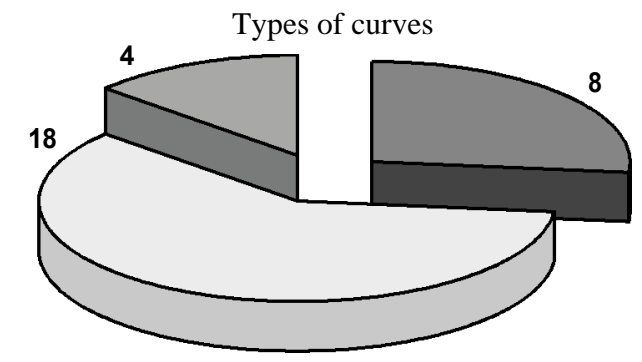

Fig. (1): Distribution of the studied cases (benign; malignant $\&$ suspicious) according to type of curves $(n=30)$.

Table (7): Distribution of the studied cases according to different parameters $(n=30)$.

\begin{tabular}{lcc}
\hline & No. & $\%$ \\
\hline High signal in diffusion images: & & \\
No & 18 & 60.0 \\
Yes & 12 & 40.0 \\
& & \\
Low signal on the corresponding ADC map: & & \\
No & 18 & 60.0 \\
Yes & 12 & 40.0 \\
ADC values: & & \\
Min.-max. & $0.67-2.20$ \\
Mean \pm SD. & $1.51 \pm 0.58$ \\
Median & \multicolumn{2}{c}{1.90} \\
Low ADC values: & & \\
No & 17 & 56.7 \\
Yes & 13 & 43.3 \\
\hline
\end{tabular}

Table (8): Distribution of the studied cases according to diffusion $(n=30)$.

\begin{tabular}{lcc}
\hline & No. & $\%$ \\
\hline Restricted diffusion (malignant criteria): & & \\
No & 17 & 56.7 \\
Yes & 13 & 43.3
\end{tabular}

Facilitated diffusion (benign criteria):

\begin{tabular}{lll} 
No & 13 & 43.3 \\
Yes & 17 & 56.7 \\
\hline
\end{tabular}

Table (9): Distribution of the studied cases according to DWI positive characer of malignancy $(n=30)$.

\begin{tabular}{ccc}
\hline DWI positive characer of malignancy & No. & $\%$ \\
\hline Malignant & 12 & 40.0 \\
Benign & 16 & 53.3 \\
Borderline & 2 & 6.7 \\
\hline
\end{tabular}

Table (10): Distribution of the studied cases according to pathological result $(\mathrm{n}=30)$.

\begin{tabular}{lll}
\hline Pathological result & No. & $\%$ \\
\hline Malignant & 11 & 36.7 \\
Benign & 18 & 60.0 \\
Borderline & 1 & 3.3 \\
\hline
\end{tabular}

Table (11): Agreement (sensitivity, specificity and accuracy) for f-MRI and conventional MRI (\% from total).

\begin{tabular}{|c|c|c|c|c|c|c|c|c|c|}
\hline & \multicolumn{4}{|c|}{ Pathological result } & \multirow{3}{*}{ Sensitivity } & \multirow{3}{*}{ Specificity } & \multirow{3}{*}{ PPV } & \multirow{3}{*}{ NPV } & \multirow{3}{*}{ Accuracy } \\
\hline & \multicolumn{2}{|c|}{$\begin{array}{l}\text { Benign } \\
(\mathrm{n}=18)\end{array}$} & \multicolumn{2}{|c|}{$\begin{array}{l}\text { Malignant } \\
(\mathrm{n}=11)\end{array}$} & & & & & \\
\hline & No. & $\%$ & No. & $\%$ & & & & & \\
\hline \multirow{2}{*}{\multicolumn{10}{|c|}{$\begin{array}{l}\text { MRI positive characer } \\
\text { of malignancy: }\end{array}$}} \\
\hline & & & & & & & & & \\
\hline Benign & 12 & 66.7 & 3 & 27.3 & 72.7 & 66.7 & 57.2 & 80 & 61.7 \\
\hline Malignant & 6 & 33.3 & 8 & 72.7 & & & & & \\
\hline \multicolumn{10}{|c|}{ f-MRI positive characer } \\
\hline \multicolumn{10}{|c|}{ of malignancy: } \\
\hline Benign & 18 & 100 & 1 & 10.1 & 90.9 & 100 & 90.9 & 94.7 & 95 \\
\hline Malignant & 0 & 0 & 10 & 90.9 & & & & & \\
\hline
\end{tabular}

PPV : Positive Predictive Value.

NPV : Negative Predictive Value.

: Statistically significant at $p \leq 0.05$. 


\section{Cases:}

49 years old female patient presented with pelvi-abdominal pain. Histo-pathological study revealed right ovarian cyst-adeno-carcinoma.

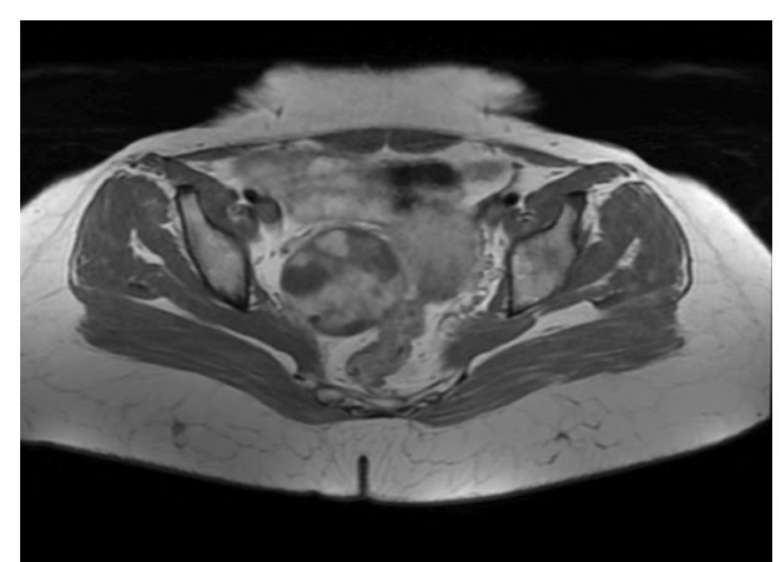

Fig. (2A): Axial T1 (A): Shows a large right adnexal mixed cystic and solid mass lesion measures 6.1 X $6.3 \mathrm{X}$ $6.4 \mathrm{~cm}$ mixed low and high signal intensity.

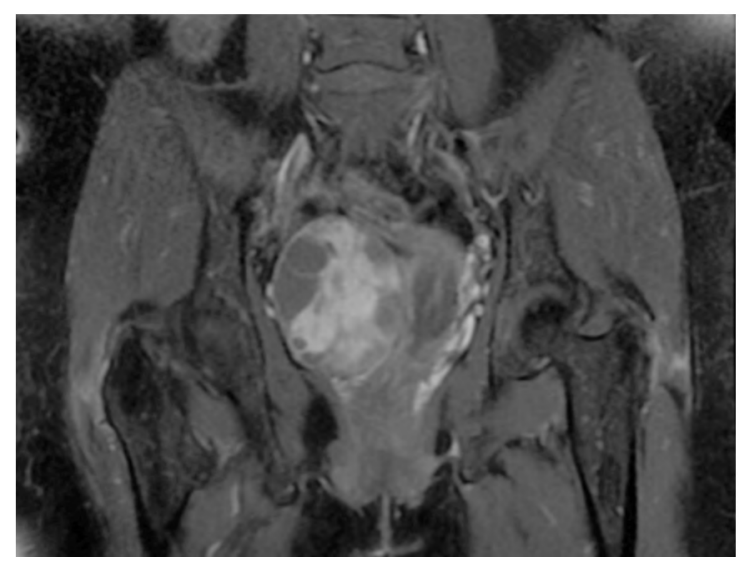

Fig. (2C): Coronal post contrastfat supressed T1; revealed enhancement of the solid parts no fat suppression.

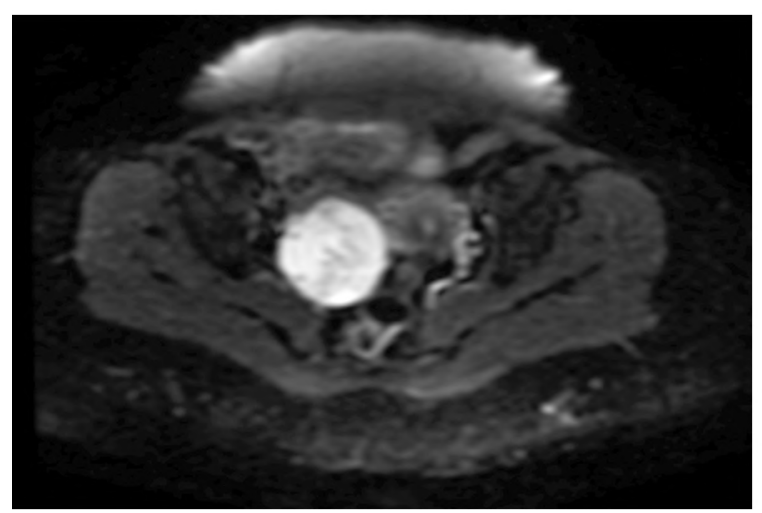

Fig. (2E): DWI diffusion restriction of the solid component.

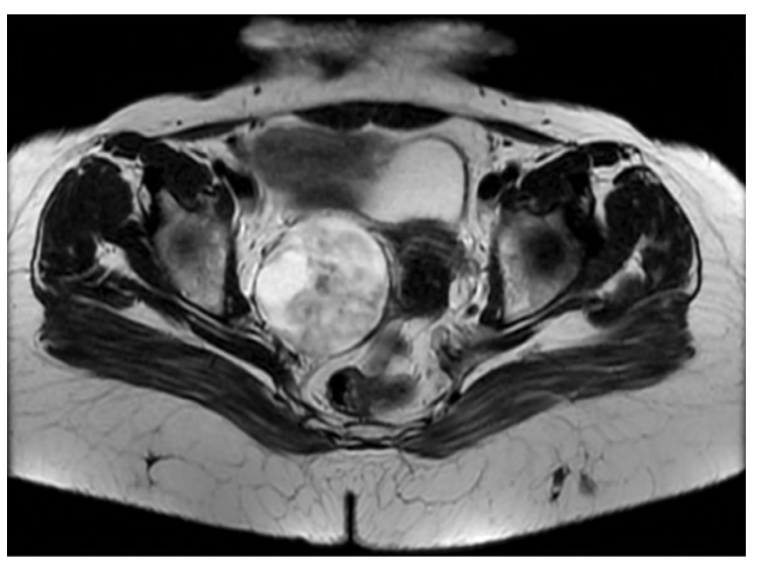

Fig. (2B): Axial T2 the lesion shows heterogenous intensity.

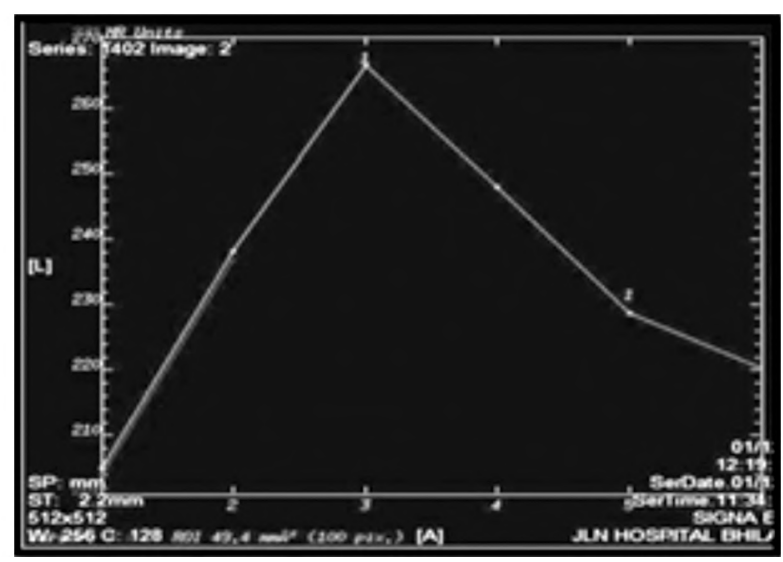

Fig. (2D): Dynamic post contrast curve with type III curve (rapid enhancement with rapid wash out).

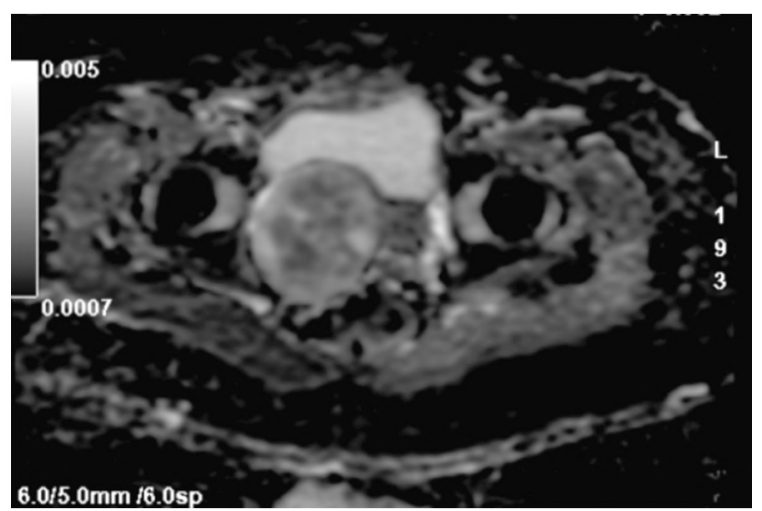

Fig. (2F): ADC map with ADC value measures $0.82 \mathrm{X}$ $10^{-3} \mathrm{~mm}^{2} / \mathrm{S}$. 
A 25-year-old-female presented with abdominal pain which increased during menstrual cycle, histopathologic exam revealed right ovarian endometrioma.

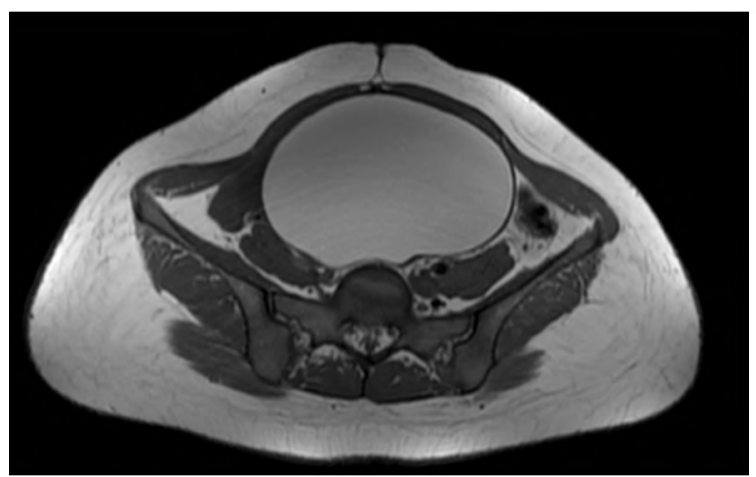

Fig. (3A): Axial T1WI; shows a large right adnexal cystic lesion measures 13.3 X 8.5 X $14.2 \mathrm{~cm}$ of homogenous high signal intensity.

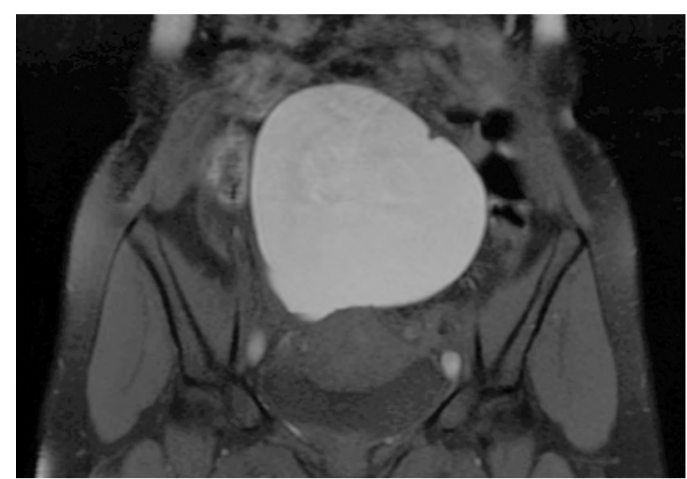

Fig. (3C): Coronal T1 fat suppresion; shows no signal suppression.

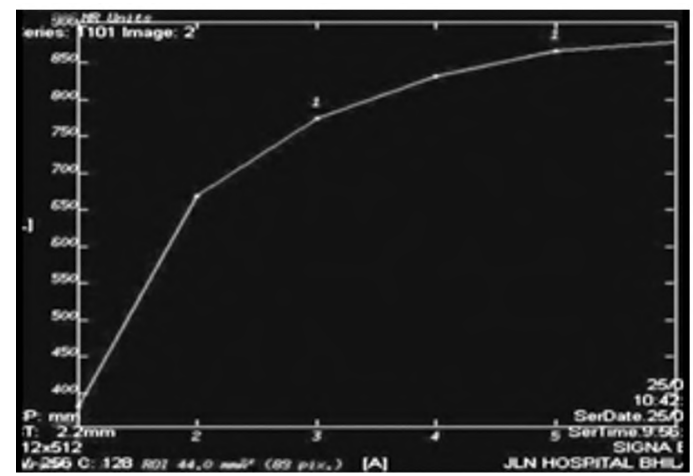

Fig. (3E): Dynamic post contrast curve; its wall shows type I curve (slow rising curve).

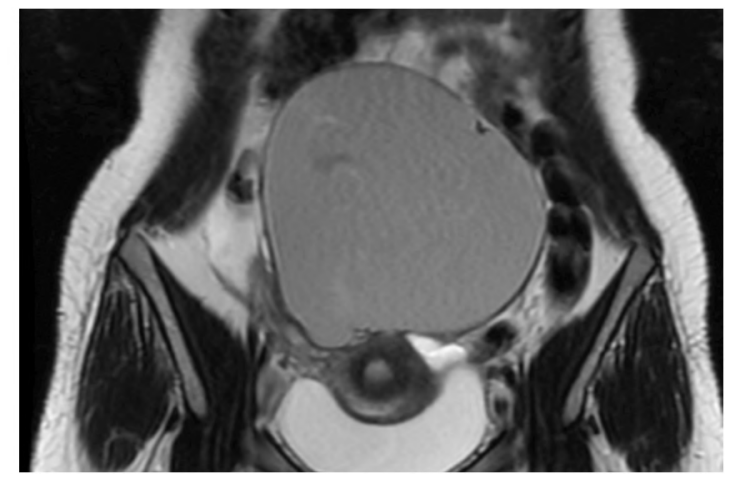

Fig. (3B): Coronal T2WI; shows intermediate signal intensity (T2 shading).

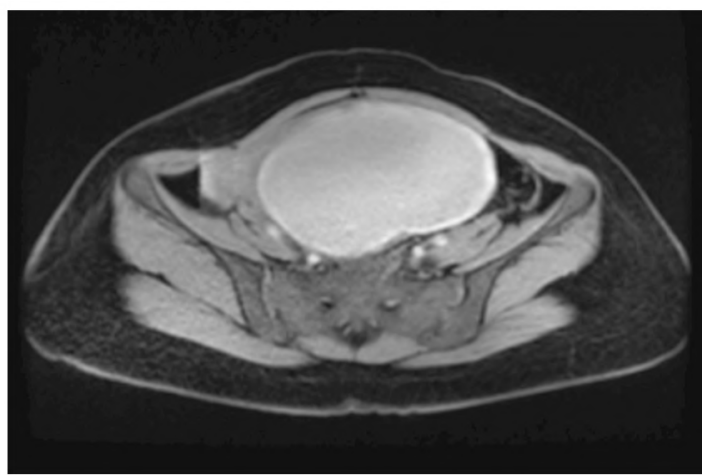

Fig. (3D): Axial T1 post contrast; revealed wall enhancement.

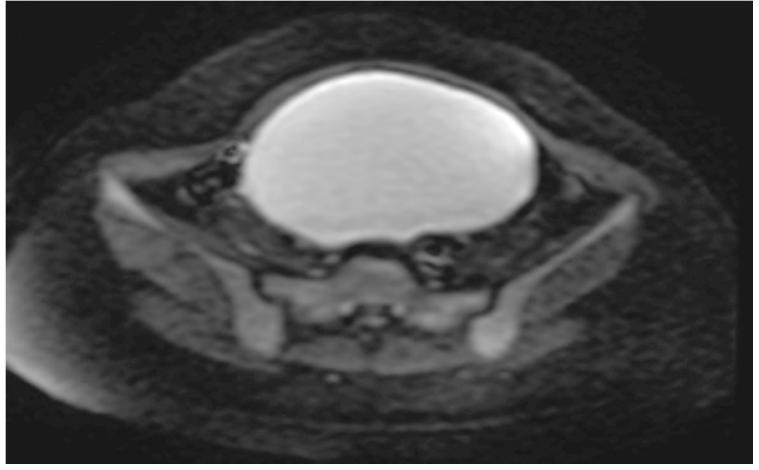

Fig. (3F): DWI; demonstrates diffusion restriction.

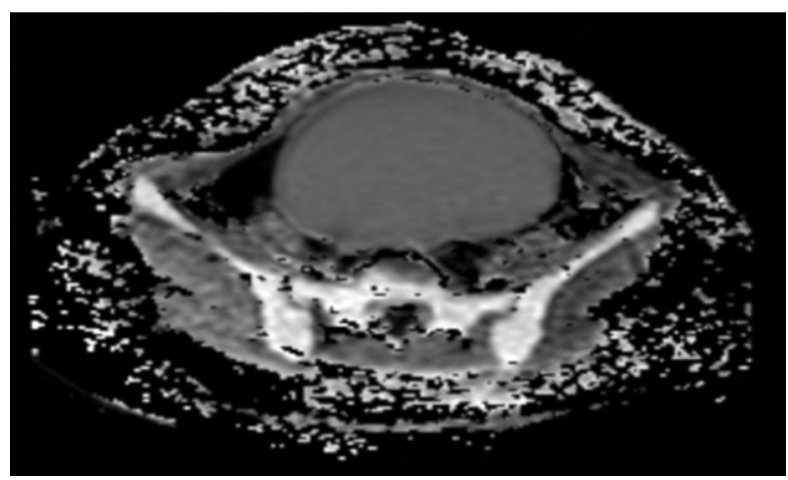

Fig. (3G): ADC map; with ADC value measures $0.74 \times 10^{-3} \mathrm{~mm}^{2} / \mathrm{s}$ 
27 years old female patient presented with pelvi-abdominal pain. Histo-pathological study revealed right Benign ovarian mucinous cyst-adenoma.

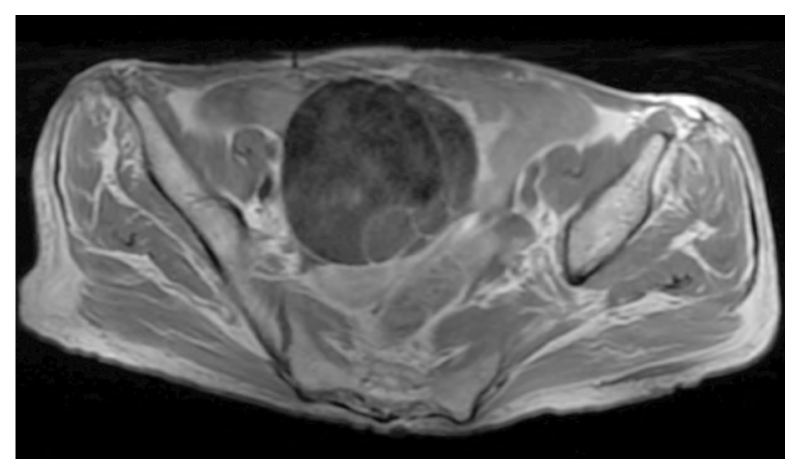

Fig. (4A): Axial T1WI; shows right multi-locular adnexal cystic lesion measuring about $10 \times 9 \mathrm{~cm}$ showing low signal intensity.

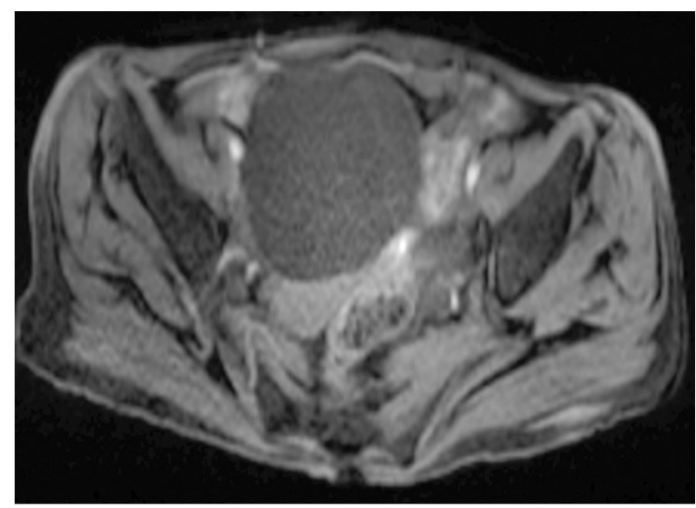

Fig. (4C): Axial T1 post contrast revealed fine marginal (wall \& septal) enhancement.

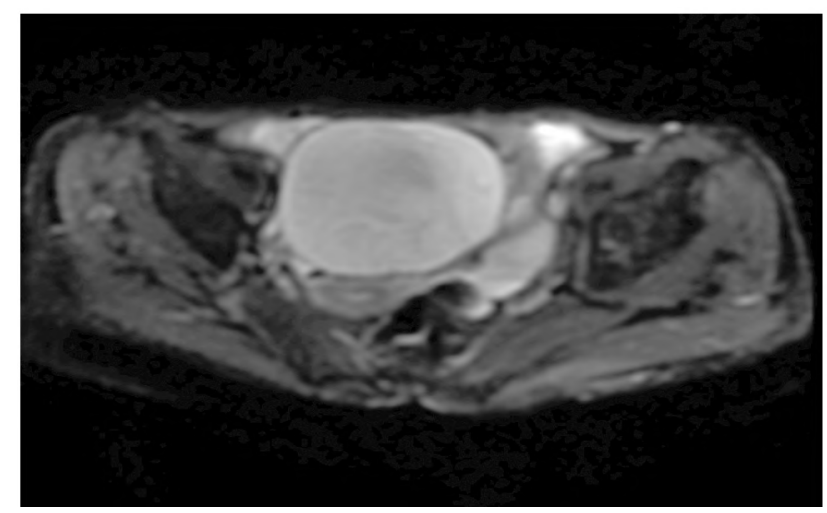

Fig. (4E): DWI; demonstratefree diffusion.

\section{Discussion}

MRI provides exquisite views of the pelvic anatomy through its high spatial resolution and tissue contrast, and as such plays a key role in the work up of ovarian lesions, identifying features that distinguish benign and malignant lesions. In the case of primary tumors it enables local staging and detection of metastatic disease to help guide management options such as complex surgery or

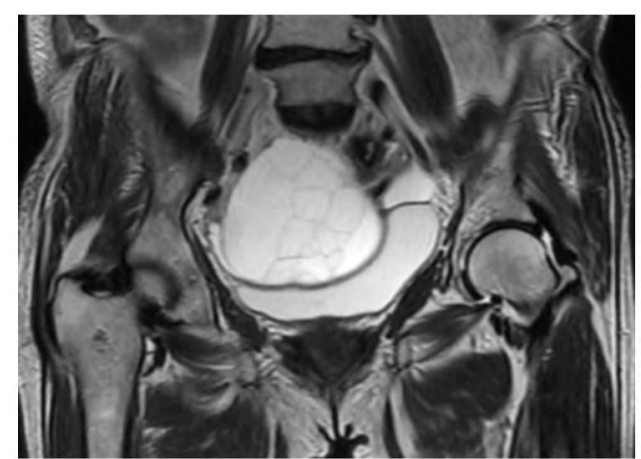

Fig. (4B): Coronal T2; shows high signal locules.

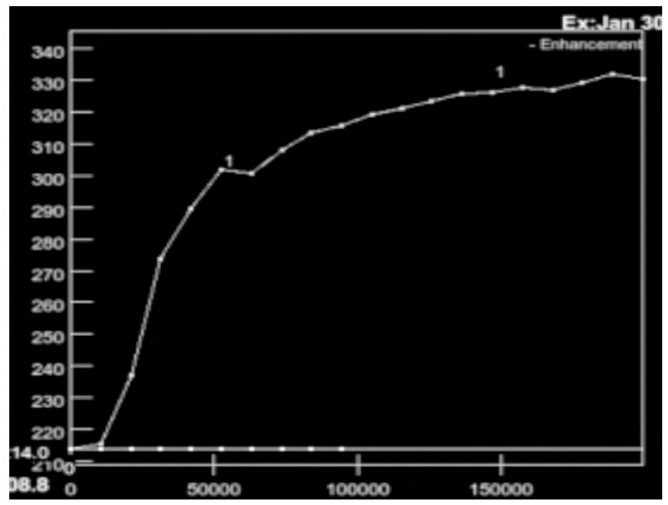

Fig. (4D): Dynamic post contrast curve; with type I curve (slow rising curve).

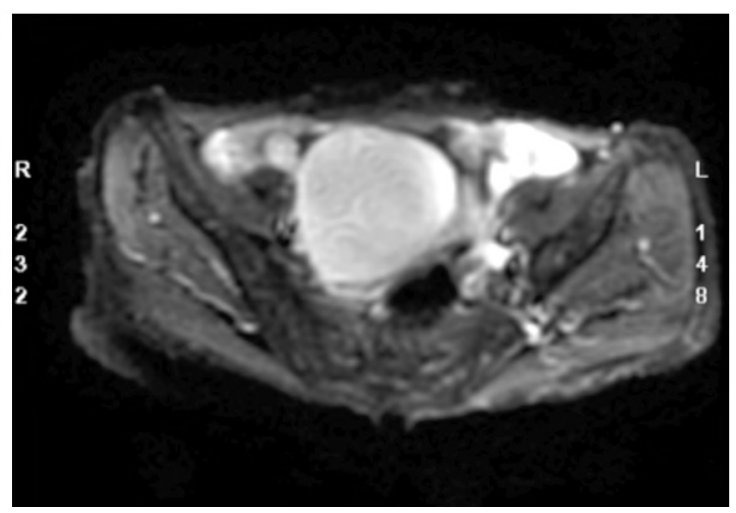

Fig. (4F): ADC map; with ADC value $=2 \times 10^{-3} \mathrm{~mm}^{2} / \mathrm{S}$.

the consideration of neoadjuvant chemotherapy [3].

DWI is a new promising diagnostic tool that can be added to conventional MRI to better characterize and differentiate benign from malignant lesions [4]

In our study, we included 30 patients with different ovarian lesions and focused on the eval- 
uation of the role of conventional MRI and diffusion MRI in differentiating between benign and malignant ovarian lesions.

In our study, pelvi-abdominal pain represents the most common complaint of the patients $(50 \%)$ which was in agreement with Liu et al., 2013 study which carried on 203 patients who presented with adnexal masses and found that pelvi-abdominal pain was the most common complaint of the patients $(57.7 \%)$ [5]

In our study, we found that lesions in the left side were more than right side $(56.7 \%, 30 \%$ respectively) and $13.3 \%$ bilateral lesions which was in disagreement with Amir, 2017 study which had $62.5 \%$ of the lesions in the right side and $37.5 \%$ in the left side, this disagreement was a mere coincidence [6].

In our study, mean patient age was 40.37 years which disagreed with Koc et al., 2012 study carried on 58 female patients concluded that mean patient age was 51 years aiming to explore the optimal bvalue in Diffusion-Weighted (DW)-MRI for differentiation of benign and malignant gynecological lesions, this disagreement may be attributed to the number of patients which is larger than our number of patients [7].

In our study, $22.7 \%$ of total 22 benign cases showed solid component and $62.5 \%$ of total 8 malignant cases showed solid component $(p<0.025)$ which was in agreement with Li et al., 2012 study which concluded that solid components were found in $11 / 46(23.9 \%)$ benign and 37/85 (43.5\%) malignant masses $(p<0.05)[8]$

In our study, we found that $37.5 \%$ of malignant cases were cystic and $62.5 \%$ of malignant cases were mixed cystic and solid but no cases were solid only, this agrees with Amir, 2017 study which found that malignant cystic lesions were $12.5 \%$ and $81.25 \%$ of malignant cases were mixed cystic and solid, also he found only one case is pure solid $(6 \%)$, we didn't found any pure solid malignant lesion which may be attributed to our smaller number of malignant cases and also large size of malignant lesions under our study which made them more liable to necrosis and presence of cystic components [6].

In our study, we found that $63.6 \%$ of benign lesions were unilocular while $37.5 \%$ of malignant lesions were unilocular, this agree with Valerio et al., 2016 which said that unilocular cystic masses in the adnexal region are more likely benign [9] .
In our study, we found that $59.1 \%$ of benign cases show high signal in T2 weighted images and only $37.5 \%$ of malignant lesions showed high signal in T2 weighted images, this disagree with Zhang et al., 2012 study which found that $52.7 \%$ of studied benign lesions (39/74) showing high signal in $\mathrm{T} 2$ weighted images and $84.3 \%$ of studied malignant lesions (108/128) showing high signal in T2 weighted images, it may be attributed to our larger number of benign cases than malignant ones [10].

In our study, we found that $9.1 \%$ of benign cases showing fat density but no malignant cases showing fat, also found that $62.5 \%$ of malignant cases are complex (cystic/solid) but only $13.6 \%$ of benign cases are complex, $95 \%$ of benign cases have no vegetations or papillary projections, mean width of malignant lesions $(8.3 \mathrm{~cm})$ is larger than in benign lesions $(6.4 \mathrm{~cm}), 85.7 \%$ of heterogeneously enhanced lesions were malignant (6 from total 7 cases), $62.6 \%$ of malignant cases show septations but only $36.4 \%$ of benign cases show septations. This was in agreement with Amir, 2017 study which carried on 84 consecutive patients (age range, 17-70 years; mean age, 30 years) with different clinical presentations such as irregular menses, pelvic pain, fever and palpable pelvic mass aiming to determine whether Magnetic Resonance Imaging (MRI) images and enhancement features could help accurately in distinguishing benign from malignant adnexal masses, he concluded that both benign and malignant masses of ovary can be distinguished on MRI according to texture whether cystic or solid, shape, size, invasion of adjacent tissue, MR imaging allows identification of blood products within hemorrhagic masses that may mimic solid tumor. Fat-suppressed T1weighted MR images may reveal small amounts of fat, which allow the diagnosis of benign adnexal masses, contrast enhanced T1-weighted MR imaging depicts features of malignancy such as enhancing mural nodules and/or enhancing solid areas with or without necrosis. The benign diagnosis on basis of fat, cystic, no septa and no invasion of adjacent structure while the malignant lesion contains solid component, nodules, vegetations [6].

In the same study, lesions which considered malignant should have complex solid-cystic component, vegetation on the wall, large size of the lesion, heterogeneous and early enhancement, presence of septa inside cystic adnexal lesion, the presence of ascites, and peritoneal invasion.

In our study, we found that $80 \%$ of malignant lesions in the study ( 8 from total 10 malignant 
lesions) shows restricted diffusion with low ADC values. This agree with Rajasri et al., 2016 study which carried on 112 female patients with initial undetermined complex adnexal masses referred for MRI based on ultrasound findings for further characterization and staging, concluded that an adnexal mass with restricted diffusion usually is a malignant lesion, this finding, that of high signal intensity on DWI in solid components, may result from a reduction in both the extracellular matrix and the diffusion space of water protons in the extracellular and intracellular dimensions due to an increased nuclear to cytoplasmic ratio and hypercellularity. However, the low signal intensity on DWI in benign ovarian tumors such as fibrothecomas, cystadenofibromas and Brenner tumors, may be due to the high density of fibers, the low cellularity [11]

In our study, we had 22 pathologically proven benign ovarian lesions, 14 cases showed facilitated diffusion and 3 cases of the rest 8 cases are hemorrhagic cysts and chocolate cyst (endometriomas) showed restricted diffusion due to high hemosiderin content, this was in agreement with Nasr et al., 2014 study which conducted on 30 cases of different ovarian lesions, twenty three cases were pathologically proved (classified to 12 benign and 11 malignant), seven cases showed facilitated diffusion (low signal in diffusion images, high signal on corresponding ADC map and high ADC values), five hemorrhagic cysts (diagnosed by MRI criteria and follow-up U/S) and 2 endometriomas (proved pathologically) showed high signal not only on diffusion images but also on corresponding ADC map and ADC values [12].

In our study, we had three cases of tubo-ovarian abscesses with restricted diffusion which was in agreement with Wang, 2016 study which carried on 34 cases of tubo-ovarian abscesses and found that all $34(100 \%)$ cases of TOA showed markedly homogeneous or heterogeneous hyperintensity in the cystic component on DW images, indicating restricted water diffusion [13].

In our study, mean ADC value of the cystic component did not differ significantly between benign and malignant masses $(p=0.195)$ as it was $1.603 \times 10^{-3} \pm 0.49 \times 10^{-3} \mathrm{~mm}_{-3} / \mathrm{s}$ for benign tumors, and $1.223 \times 10^{-3} \pm 0.53 \times 10^{-3} \mathrm{~mm}^{2} / \mathrm{s}$ for malignant tumors which also considered statistically insignificant. This was in agreement with Li et al., 2012 study which carried on 127 patients with pelvic masses, (46 benign and 85 malignant), the purpose of this study was to evaluate differences in ADC values for differentiating benign versus malignant ovarian tumors pre-operatively, they concluded that the mean ADC value of the çystic component $=2.58 \times 10^{-3} \pm 0.27 \times 10^{-3} \mathrm{~mm}^{2} / \mathrm{s}$ for benign tumors, and $2.44 \times 10^{-3} \pm 0.33 \times 10^{-3} \mathrm{~mm}^{2} / \mathrm{s}$ for malignant tumors which found to be statistically insignificant [8]

On the other hand, we found that mean ADC value of the solid component can differs significantly between benign and malignant masses $(p$ $<0.001)$ as it was $1.176 \times 10^{-3} \pm 0.15 \times 10^{-3} \mathrm{~mm} / \mathrm{s}$ for benign tumors, and $0.747 \times 10^{-3} \pm 0.12 \times$ $10^{-3} \mathrm{~mm} / \mathrm{s}$ for malignant tumors which also considered statistically significant which was in agreement with the same study which concluded that DWI is beneficial for differentiating between benign and malignant ovarian lesions regarding to solid components as they found that the mean ADC value of the solid component $=1.69 \times 10^{-3} \pm 0.25$ $\times 10^{-3} \mathrm{~mm}^{2} / \mathrm{s}$ for benign tumors, and $1.03 \times 10^{-3} \pm$ $0.22 \times 10^{-3} \mathrm{~mm}^{2} / \mathrm{s}$ for malignant tumors which found to be statistically significant.

In our study, the sensitivity, specificity, PPV, NPV and accuracy of conventional MR imaging all have increased from $72.7 \%, 66.7,57.14 \%, 80 \%$, $61.5 \%$ respectively for conventional MRI to $90.9 \%$, $100 \%, 90.9 \%, 94.7 \%, 95 \%$ respectively for f-MRI. Which was in agreement with Li et al., 2012 study which concluded that the sensitivity, specificity, PPV, NPV and accuracy of conventional MR imaging all have increased after adding DWI to the conventional MRI [8].

In ${ }_{-3}$ our study, we found that $\mathrm{ADC}$ value $\geq 1.16$ $X 10^{-3} \mathrm{~mm} / \mathrm{s}$ may be the optimal cutoff for differentiating between benign and malignant tumors which was in agreement with Zhang et al., 2012 study carried on 191 female patients with different ovarian lesions underwent Diffusion Weighted (DW) Magnetic Resonance (MR) imaging of 202 ovarian masses aiming to evaluate the role of DWI in differentiating between benign and malignant ovarian lesions, they concluded that ADC value $\geq 1.20 \times 10^{-3} \mathrm{~mm}^{2} / \mathrm{s}$ may be the optimal cutoff for differentiating between benign and malignant tumors [10].

\section{Conclusion:}

MR imaging is used as a problem-solving tool for confusing ovarian lesions, characterizing benign and malignant ovarian tumors; moreover, it enables a specific diagnosis for certain pathologic types. Combination of conventional MRI \& f-MRI findings are very useful in the diagnosis and followup of patients with gynecological diseases. 


\section{References}

1- PIERCE N., NARAYANAN P., SAHDEV A., et al.: Ovarian lesions pose diagnostic dilemmas: Diagnostic Imaging Europe, 24 (3): 14-18, 2008.

2- VALENTINI L., GUI B., MICCO M., et al.: Benign and Suspicious Ovarian Masses-MR Imaging Criteria for Characterization: Pictorial Review: Journal of Oncology, $1-9,2012$.

3- ALBERTO H., BARRETT T. and SALA E.: MRI of ovarian masses: JMRI, 37 (2): 265-28, 2013.

4- KHALED A. and ABDRABOU A.: The significance of added ADC value to conventional MR imaging in differentiation between benign and malignant ovarian neoplasms: The Egyptian Journal of Radiology and Nuclear Medicine, 45: 997-1002, 2014.

5- LIU H., WANG X., LU D., et al.: Ovarian masses in children and adolescents in China: Analysis of 203 cases: Journal of Ovarian Research, 6: 47, 2013.

6- AMIR K.: Validity of Magnetic Resonance Imaging (MRI) in characterizing adnexal masses: A prospective study: Journal of Chemical and Pharmaceutical Sciences, 10 (1): 142,2017

7- KOC Z., ERBAY G., ULUSAN S., et al.: Optimization of $b$ value in diffusion-weighted MRI for characterization of benign and malignant gynecological lesions: JMRI, 35 (3): 650-9, 2012.
8- LI W., CHU C., CUI Y., et al.: Diffusion-weighted MRI: A useful technique to discriminate benign versus malignant ovarian surface epithelial tumors with solid and cystic components: Abdominal Imaging, 37: 897-903, 2012.

9- VALERIO P., ATTINA G., SPADOLA S., et al.: MR imaging of ovarian masses: Classification and differential diagnosis: Insights Imaging, 7 (1): 21-41, 2016.

10- ZHANG P., CUI Y., LI W., et al.: Diagnostic accuracy of diffusion weighted imaging with conventional MR imaging for differentiating complex solid and cystic ovarian tumors at 1.5T: World Journal of Surgical Oncology, 10 (1): 237, 2012.

11-RAJASRI B., PRASAD H. and SREE S.: Role of Diffusion Weighted MR Imaging in Adnexal lesions in Female Pelvis A Prospective study: JMSCR, 4 (9): 12675-85, 2016.

12-NASR E., HAMED I., ABBAS I., et al.: Dynamic-contrast enhanced MRI in correlation with diffusion weighted (DWI) MR for characterization of ovarian masses, The Egyptian Journal of Radiology and Nuclear Medicine, 45 (3): 975-85, 2014.

13- WANG T., LI W., WU X., et al.: Tubo-Ovarian Abscess (with/without Pseudotumor Area) Mimicking Ovarian Malignancy: Role of Diffusion-Weighted MR Imaging with Apparent Diffusion Coefficient Values: PLOS ONE, 11 (2): e0149318, 2016. 


\section{فائدة الرنين المغناطيسى الوظيفى فى تقييم آفات المبيض}

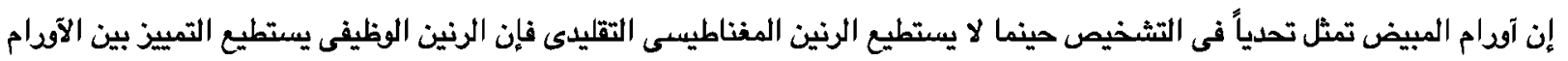

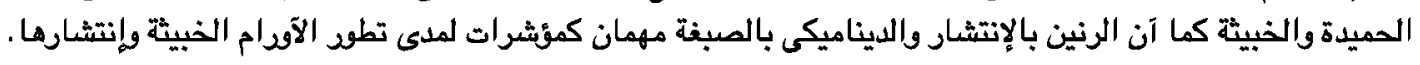
الهدف من البحث: التمييز بين الآوام الحميدة والخييثة المبيض بإستخدام الرنين المفناطيسى الوظليفى كآداة حديثة آفضل للتفرقة. المرضى وطرق البحت: تشتمل هذه الدراسة على ثلاثين مريضة تعانى من آودام بالمبيض بقسم الآثعة التشخيصية يتم تحويلهن من قسم النسا والتوليد وقسم الآورام بمستشفيات جامعة طنطا. معايير الإشتمال: المرضى اللاتى تعانى من:

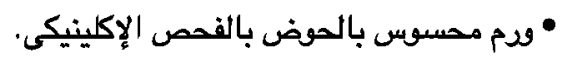
• مشاكل نسائية. • ودم قديم بالمبيض. معايير الإستبَعاد : المرضى اللاتى لديهن:

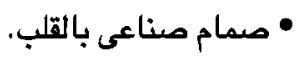
• خوف مرخى من الآماكن المغلقة. • تاريخ سابق بحدوث مضاعفات نتيجة إستخدام الصبغة.

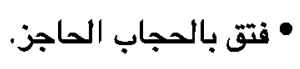
• • آنابيب مغذية. الطرق: • آخذ التاريخ المرضى الكامل. • • الفحص السريرى الكامل ومراقبة العلامات الحيوية. • فحص التحاليل الطبية للمريضة. • مراجعة الآشعات السابقة إذا توافرت مع المريضة التهائة • تم مقارنة نتائج الرنين مع نتائج التحاليل النسيجية للآودام. ويمكننا آن نستنتج آن المزج بين الرنين المغناطيسى التقليدى والوظيفى حل مشكة التفرقة بين آودام المبيض الحميدة والخبيثة. 